\title{
EFEITO DA SUPLEMENTAÇÃO DE FITASE NA ALIMENTAÇÃO DE JUVENIS DE TAMBAQUI (COLOSSOMA MACROPOMUM)
}

\author{
EFFECT OF PHYTASE SUPPLEMENTATION FOR JUVENILES OF TAMBAQUI \\ (COLOSSOMAMACROPOMUM)
}

\author{
Mendonça, P.P. ${ }^{1 *}$, Costa, P.C. ${ }^{2}$, Polese, M.F. ${ }^{3}$, Vidal Jr, M.V. ${ }^{4}$ e Andrade, D.R. ${ }^{4}$
}

${ }^{1}$ Setor de Aquicultura. Instituto Federal do Espírito Santo (IFES). Campos Alegre. Alegre, Espírito Santo. Brasil. *ppmendonca@ifes.edu.br

${ }^{2}$ Centro de Ciências Agrárias. Universideda Federal do Espírito Santo. Brasil.

${ }^{3}$ Instituto Federal do Espírito Santo (IFES). Campos Piúma. Brasil.

${ }^{4}$ Universidade Estadual do Norte Fluminense Darci Ribeiro. Campos dos Goytacazes. Rio de Janeiro. Brasil.

\section{PalaVRas chaVe adicionais}

Fitato. ATP. Fisiologia. Peixe.

\section{RESUMO}

O presente experimento foi realizado na Universidade Estadual do Norte Fluminense Darcy Ribeiro, no setor de aqüicultura, objetivando-se avaliar a suplementação de fitase para alevinos de tambaqui (Colossoma macropomum). Foram utilizados 170 alevinos com peso inicial médio de, $3,12 \pm 0,05 \mathrm{~g}$ e comprimento total médio inicial de $5,36 \pm 0,06 \mathrm{~cm}$. Os alevinos foram distribuídos aleatoriamente, em 20 aquários experimentais de volume útil $40 \mathrm{~L}$, com abastecimento de água proveniente de um sistema de circulação fechado, equipado com filtro biológico. Os tratamentos foram constituídos de cinco dietas isoprotéicas e isocalóricas ( $28 \%$ de proteína e $3100 \mathrm{kcal}$ de ED/ $\mathrm{kg}$ de dieta), suplementadas com quatro níveis de fitase exógena $(700,1400,2100$ e $2800 \mathrm{UAF} / \mathrm{kg}$ de dieta) mais uma sem suplementação. A adição de fitase as dietas, foi realizada durante a mistura dos ingredientes para fabricação das dietas peletizadas. Foi verificado o efeito da suplementação de fitase sobre as variáveis mensuradas, sendo a menor dose estimada igual a 1540,62UFA $\mathrm{kg}^{-1}$ de dieta, para variável consumo de ração e a maior dose estimada igual a 2303,83 UFA kg-1 de dieta, para variável taxa de desenvolvimento especifica. As doses estimadas no presente trabalho são superiores às encontradas em trabalhos que citam o efeito da suplementação sobre os peixes. Entretanto a dose de suplementação, assim como a idade e outros fatores podem ser motivos de

Recibido: 15-4-11. Aceptado: 23-2-12.

\section{AdDitional KeYWORDS}

Phytate. ATP. Physiology. Fish.

verificação ou não da ação da fitase sobre o desenvolvimento dos peixes. Ao final do experimento, concluiu-se que a fitase influenciou o desenvolvimento dos juvenis de tambaqui a partir da dose estimada em 1540,62 UFA kg-1 de dieta.

\section{SUMMARY}

This experiment was conducted the Norte Fluminense State University Darcy Ribeiro in the aquaculture sector, aiming to evaluate the supplementation of phytase for juvenile tambaqui (Colossoma macropomum). It was used a total of 170 fingerlings with average initial weight of $3.12 \pm 0.05 \mathrm{~g}$ and initial total length with the average of $5.36 \pm 0.06 \mathrm{~cm}$. The fingerlings were randomly distributed in 20 experimental tanks with an useful volume of $40 \mathrm{~L}$, being the water supplied from a closed circulation system, equipped with a biological filter. The treatments consisted of five isoproteic and isocaloric diets $(28 \%$ protein and $3100 \mathrm{kcal} \mathrm{ED} / \mathrm{kg}$ diet), supplemented with four levels of exogenous phytase $(700,1400,2100$ and $2800 \mathrm{UAF} / \mathrm{kg}$ diet) with one more without supplementation. The addition of phytase to the diets was done during the mixing of the ingredients for the manufacture of pelleted diets. It was verified the effect of phytase supplementation on the measured variables, being the smallest estimated dose equal to 1540.62 UFA kg-1 of diet 
MENDONÇA, COSTA, POLESE, VIDAL JR E ANDRADE

for feed intake variable and the higher estimated dose equal to $2303.83 \mathrm{UFA} \mathrm{kg}^{-1}$ of diet for variable rate of specific development. The doses estimated in this study are much higher than those found in studies that mention the effect of supplementation on the fish, although the dose of supplementation, as well as age and other factors may be grounds, or not, for checking the action of phytase on the development of fish. At the end of the experiment, it was concluded that phytase influenced the development of tambaqui from the estimated dose, 1540.62 UFA kg$^{-1}$, of diet.

\section{INTRODUÇÃO}

Dentre as espécies nativas produzidas pela piscicultura brasileira, o tambaqui (Colossoma macropomum) e a espécie mais produzido e comercializado no Brasil, com um total médio produzido em 2009 de 46 454,00 toneladas (MPA, 2009). Este fato esta ligado diretamente com as características de produção que essa espécie possui: boa adaptação ao cativeiro, boa aceitação no mercado, alta prolificidade, hábito alimentar onívoro, bom crescimento, boa conversão alimentar e rusticidade. (Menezes, 2005).

A alimentação pode corresponder a valores acima de $60 \%$ dos custos de produção, e melhorias na eficiência da utilização dos nutrientes resultam em economias significativas. Assim, torna-se importante o conhecimento da utilização dos nutrientes como a proteína, os lipídios, os carboidratos, as vitaminas e os minerais nas formulações de rações para produção de dietas de baixo custo. Assim minerais como fósforo podem influenciar na eficiência das dietas, pois, de acordo com Lehninger et al. (1993), a maioria do fósforo nos grãos de cereais está na forma do complexo orgânico fitato. Devido ao grupo ortofosfato do fitato ser altamente ionizado, este se complexa com uma variedade de cátions ( $\mathrm{Ca}, \mathrm{Fe}, \mathrm{Zn}, \mathrm{Mn}$ ) e com o grupo amina de alguns aminoácidos, tornando-se indisponível para alimentação de peixes e demais animais monogástricos, pela ausência da enzima fitase.
O fósforo é um nutriente essencial, e a sua deficiência acarreta uma redução na taxa de crescimento, redução na eficiência alimentar e baixa na mineralização óssea (Furuya et al., 2001).

Nos peixes, aproximadamente 85 a $90 \%$ do fósforo estão presente nos ossos e escamas (Lovell, 1988). A deficiência de fósforo pode resultar na redução do apetite, retardo no crescimento e anemia hipocrômica microcítica. Em alguns casos, convulsão seguida de morte, além de escoliose e lordose. Além disso, pode causar deformidade e hipodensidade de minerais nas vértebras pela baixa mineralização(Helland et al.,2006).

Souza (2008) comenta sobre a ação da fitase sobre o fitato, que acarreta em maior disponibilidade de fósforo para a absorção pelo intestino. Essa maior disponibilidade de fosforo pode melhorar o desempenho, a digestibilidade e a disponibilidade dos nutrientes da dieta, além de reduzir a excreção do fósforo presente no fitato. Assim, a utilização de dietas suplementadas com fitase tem-se mostrado cada vez mais importante, uma vez que pode favorecer a criação de peixes com redução do impacto ambiental. $\mathrm{O}$ objetivo deste trabalho foi avaliar a resposta dos alevinos de tambaqui à suplementação de fitase exógena em diferentes dosagens.

\section{MATERIAL E MÉTODOS}

O presente experimento foi realizado no Brasil, estado do Rio de Janeiro na cidade de Campos dos Goytacazes, na Universidade Estadual do Norte Fluminense Darcy Ribeiro, no setor de aqüicultura. O período de duração do experimento foi de 23 de março a 13 de maio de 2010, totalizando 50 dias de experimentação.

Para realização do experimento foram utilizados 170 alevinos de tambaqui (Colossoma macropomum) com peso inicial médio de, $3,12 \pm 0,050$ g e comprimento total médio inicial de $5,36 \pm 0,06$. Os alevinos foram distribuídos aleatoriamente, em 20 aquários experimentais de volume útil $40 \mathrm{~L}$, 
com abastecimento de água proveniente de um sistema de circulação fechado, equipado com filtro biológico, aquecedores com termostatos para manutenção da temperatura da água.

$\mathrm{O}$ delineamento experimental adotado foi o inteiramente casualizado, com cinco tratamentos, quatro repetições, totalizando 20 unidades experimentais. Cada unidade experimental foi composta por um aquário com 7 alevinos de tambaqui, com entrada e saída de água independentes.

Os tratamentos foram constituídos (tabela I) de cinco dietas isoprotéicas e isocalóricas (28\% de proteína e $3100 \mathrm{kcal}$ de $\mathrm{ED} / \mathrm{kg}$ de dieta), suplementadas com quatro níveis de fitase exógena $(700,1400,2100$ e 2800 UFA $/ \mathrm{kg}$ de dieta) mais uma sem suplementação. A adição de fitase as dietas, foi realizada durante a mistura dos ingredientes para fabricação das dietas.

O produto utilizado para suplementação de fitase (Natuphos ${ }^{\circledR}$ 5000, BASF, Germany) apresenta concentração de $5000 \mathrm{UFA} / \mathrm{g}$ de produto. Ressalta-se que uma unidade de fitase ativa (UFA) é a quantidade de fitase que libera fósforo inorgânico do fitato de sódio $(5,1 \mathrm{mM})$ a uma taxa de $1 \mu \mathrm{mol} / \mathrm{min}$ em pH 5,5 e temperatura de $37^{\circ} \mathrm{C}$ (Kornegay, 1999).

O período pré-experimental, para a adaptação dos juvenis às condições de laboratório, foi de cinco dias, durante os quais todos receberam a ração experimental sem adição de fitase, fornecida em quatro vezes por dia.

Para a confecção das rações os alimentos foram finamente moídos em moinho de martelo, com peneira de $0,5 \mathrm{~mm}$, misturado em misturador industrial tipo Y. A mistura então foi umedecida e peletizada. Após a peletização a ração foi seca à sombra e passada em peneira para padronização no tamanho dos peletes, os quais foram adequados ao tamanho da boca dos peixes. As rações foram acondicionadas em embalagens plásticas, identificadas e armazenadas em geladeira.
O oxigênio dissolvido e temperatura foram mensurados diariamente, após a ultima alimentação do dia, através de oxímetro e termômetro digital. Os valores de $\mathrm{pH}$ foram mensurados com auxilio de um pHmetro digital com duas casas decimais. A condu-

Tabela I. Composição percentual da ração experimental. (Percentage composition of experimental diet).

\begin{tabular}{|c|c|}
\hline Ingredientes & na bruta $28 \%$ \\
\hline Farinha de peixe & 32,28 \\
\hline Farelo de soja & 13,83 \\
\hline Fubá de milho & 46,65 \\
\hline Farelo de trigo & 2,00 \\
\hline Óleo de soja & 5,03 \\
\hline Mistura vitamínica ${ }^{1}$ & 0,10 \\
\hline Mistura mineral $^{2}$ & 0,10 \\
\hline $\mathrm{BHT}$ & 0,01 \\
\hline Total (\%) & 100 \\
\hline \multicolumn{2}{|l|}{ Composição nutricional } \\
\hline Proteína bruta $(\%)^{3}$ & 27,98 \\
\hline Extrato etéreo $(\%)^{3}$ & 9,37 \\
\hline Matéria mineral $(\%)^{3}$ & 9,31 \\
\hline Energia metabolizável (kcal EM/kg) & 3101 \\
\hline Cálcio $(\%)^{4}$ & 2,04 \\
\hline Fósforo $(\%)^{4}$ & 1,03 \\
\hline Metionina $(\%)^{4}$ & 0,71 \\
\hline Metionina + Cistina $(\%)^{4}$ & 1,09 \\
\hline Lisina $(\%)^{4}$ & 2,02 \\
\hline Triptofano $(\%)^{4}$ & 0,36 \\
\hline Arginina $(\%)^{4}$ & 1,87 \\
\hline
\end{tabular}

${ }^{1}$ Rovimix Aves inicial (Roche): níveis de garantia por kg de produto: Vitaminas A- 12000 UI; D3- 2500 UI; E- 30000 UI; B1-2,0 G; B6- 3,0 G; Pantotenico de cálcio- 10,0 g; Cloreto de Colina- 100,0 g; BHT$5,0 \mathrm{~g}$; Vitamina B12- 15,000 mcg; Olaquindox- 5,0 g; Selênio- $0,120 \mathrm{~g}$.

${ }^{2}$ Roligomix Aves (Roche): Níveis de garantia por kg do produto: Manganês- 160,0; Ferro- 100,0 g; Zinco-100,0 g; Cobre-20,0 g; Cobalto-2,0 g; lodo$2,0 \mathrm{~g}$.

${ }^{3}$ Calculado a partir de dados tabelados (Vidal Junior, 1995).

${ }^{4}$ Calculada a partir de dados tabelados (Rostagno et al., 1983). 
tividade elétrica foi medida com o auxílio de um condutivímetro.

A sobrevivência foi acompanhada diariamente e a cada dez dias três alevinos foram pesados e medidos individualmente para avaliação do peso, para adequação das taxas alimentares, até completar os 50 dias de experimentação. O desempenho produtivo foi avaliado pela conversão alimentar aparente, taxa de eficiência protéica, taxa de crescimento específico.

Conversão alimentar aparente $=$ (peso final - peso inicial)/alimento consumido no período;

Taxa de eficiência protéica $=($ peso final peso inicial)/total de proteína ingerida;

Taxa de crescimento específico $=[(\log$ peso final $-\log$ peso inicial $) / n^{\circ}$ de dias experimentais)] X 100;

Taxa de desenvolvimento específico $=[(\log$ CT final $-\log C T$ inicial $) / n^{\circ}$ de dias experimentais)] X 100 .

Para cada variável mensurada no experimento foi realizada uma anova geral, onde observou-se a existência ou não do efeito do tratamento sobre as variáveis mensuradas. Após observação positiva foi feita a analise de regressão polinomial de cada variável. Todos os cálculos foram realizados com auxílio do programa estatístico SAEG(2007).

\section{RESULTADOSEDISCUSSÃO}

Os valores dos parâmetros relacionados à qualidade da água, oxigênio dissolvido, temperatura da água, $\mathrm{pH}$ e condutividade elétrica, mensurados neste experimento, estão na tabela II

O teor médio de oxigênio dissolvido, durante o período experimental, foi de 5,75 mg/L. Segundo Araújo-Lima e Gomes (2005), o tambaqui tem seu crescimento normal em níveis de oxigênio acima de $3 \mathrm{mg} / \mathrm{L}$, portanto os valores obtidos no experimento ora descrito atendem perfeitamente a exigência do tambaqui. Da mesma forma, as médias dos valores de $\mathrm{pH}$ mantiveram-se dentro dos padrões recomendados por Aride et al. (2004), entre 5,0 e 6,5. A temperatura dos aquários experimentais mostrou-se adequada para espécies de clima tropical, apresentando médias entre $28,0^{\circ} \mathrm{C}$.

Com relação aos resultados obtidos com a biometria realizada no presente trabalho, foram observadas maiores respostas quanto as variáveis, comprimento total, comprimento padrão e peso final, nos tratamentos com suplementação de fitase (tabela III).

A sobrevivência não foi afetada, demonstrando que a suplementação de fitase não possui efeito sobre essa variável, assim como foi percebido por Rocha et al. (2007), o mesmo foi observado também por Furuya et al. (2001 e 2004) para juvenis de tilápias do Nilo.

As melhores respostas (tabela III ) estão sempre acima da dose de 1400 UFA/kg de ração (T3). O análise de regressão realizada com intuito de estimar a dose de fitase que dará melhor resposta em desenvolvimento, indica que as variáveis apresentaram

Tabela II. Parâmetros de qualidade de água do experimento com suplementação de fitase. (Water quality parameters of the experiment with supplemental phytase).

\begin{tabular}{lccccc}
\hline & \multicolumn{5}{c}{ Tratamentos (UFA/kg de ração) } \\
& 0 & 700 & 1400 & 2100 & 2800 \\
\hline $\mathrm{pH}$ & 5,9 & 5,8 & 5,7 & 5,8 & 5,8 \\
Oxigênio dissolvido $(\mathrm{mg} / \mathrm{L})$ & 5,5 & 5,8 & 5,2 & 5,9 & 5,4 \\
Temperatura $\left({ }^{\circ} \mathrm{C}\right)$ & 28,67 & 28,78 & 28,75 & 29,03 & 28,85 \\
Condutividade $(\mu \mathrm{S})$ & 466 & 403 & 435 & 436 & 448 \\
\hline
\end{tabular}

Archivos de zootecnia vol. 61, núm. 235, p. 440. 
comportamento quadrático $(\mathrm{p}>0,05)$, sendo elas descritas da seguinte forma:

Peso final $=18,114+0,00371102 x-0,000000867070$ $\mathrm{X}^{2},\left(\mathrm{R}_{\text {just. }}^{2}=0,97\right)$,

CT $=9,4764+0,000490857 x-0,000000114286 x^{2}$, $\left(R_{\text {iust. }}^{2}=0,87\right)$,

$C P=7,92086+0,000415408 x-0,0000000940233 x^{2}$,

$\left(R_{\text {just. }}^{2}=0,84\right)$,

$H=4,17464+0,000288163 x-0,0000000641399 x^{2}$, $\left(R_{\text {just. }}^{2}=0,95\right)$.

onde:

$\mathrm{CT}=$ comprimento total;

$\mathrm{CP}=$ comprimento padrão;

$\mathrm{H}=$ altura.

Para as quatro variáveis citadas, foram estimados os pontos de máxima de cada parábola descrita pela regressão $(2139,98$; 2147,49; 2209,07 e 2246,36 UAF/kg de ração) para as seguintes variáveis, peso final, comprimento total, comprimento padrão e altura, respectivamente.

Estes valores de suplementação estimados no presente trabalho são superiores aos valores encontrados por Furuya et al., (2001) trabalhando com alevinos de tilápia (Oreochromis niloticus) estimaram uma dose máxima de 700 UFA/kg de ração, assim como Rocha et al. (2007) trabalhando com alevinos de jundiá (Rhamdia quelen) concluíram que a suplementação com fitase até $1500 \mathrm{UAF} / \mathrm{kg}$ de ração apresenta efeito positivo sobre variáveis de desenvolvimento e Furuya et al. (2008) que trabalharam com alevinos de pacu (Piaractus mesopotamicus) encontraram valores máximos para o desenvolvimento de 433,33UF/ $\mathrm{kg}$ de ração. Estes resultados mostram que a suplementação de fitase em dietas para peixes em fase inicial de vida pode variar bastante entre espécies diferentes.

De acordo com Silva et al. (2005), a suplementação de fitase não afeta a digestibilidade dos nutrientes da dieta fornecida para alevinos de tilápia nilótica. Sajjadi e Carter (2004) também não verificaram efeitos positivos da suplementação de fitase sobre a digestibilidade da dieta fornecida para salmão do atlântico. Quando uma ração passa pelo processo de extrusão as moléculas dos nutrientes desta ração expandem, principalmente o amido, devido à alta pressão combinada com a elevada temperatura e umidade, resultando em uma ração com melhor digestibilidade. Uma vez que a ração utilizada no presente trabalho não foi extrusada e sim peletizada, provavelmente não melhorou alterou a digestibilidade dessa ração e conseqüentemente causou uma maior necessidade de suplementação com fitase, para se obter os resultados desejados.

Por outro lado, sugere-se que a base da ração também possa ter influenciado a resposta da suplementação no presente

Tabela III. Peso final (PF), comprimento total $(C T)$, comprimento padrão $(C P)$, altura $(H)$ e sobrevivência de alevines de tambaqui com suplementação de fitase. (Final weight (PF), total length $(\mathrm{CT})$, standard length $(\mathrm{CP})$, height $(\mathrm{H})$ and survival of juveniles Colossoma macropomum supplemented with phytase).

\begin{tabular}{lcccccr}
\hline & \multicolumn{5}{c}{ Tratamentos } & (UFA/kg de ração) \\
& 0 & 700 & 1400 & 2100 & 2800 & CV \\
\hline PF $(\mathrm{g})$ & 18,04 & 20,39 & 21,77 & 21,77 & 21,84 & 7,90 \\
CT $(\mathrm{cm})$ & 9,45 & 9,82 & 9,96 & 9,92 & 9,99 & 2,27 \\
CP $(\mathrm{cm})$ & 7,90 & 8,21 & 8,36 & 8,29 & 8,39 & 2,40 \\
H $(\mathrm{cm})$ & 4,19 & 4,32 & 4,45 & 4,53 & 4,47 & 3,09 \\
Sobrevivência (\%) & 100 & 100 & 100 & 100 & 100 & 0,00 \\
\hline
\end{tabular}




\section{MENDONÇA, COSTA, POLESE, VIDAL JR E ANDRADE}

trabalho, pois segundo Bock et al.(2007) em estudos com alevinos de tilápia do Nilo perceberam que dietas com baixos níveis de fósforo disponível restringiram a utilização da proteína dietética. Como a ração base para o presente trabalho não tinha uma base vegetal e sim uma base mista, a mesma provavelmente apresenta uma pequena porcentagem de fósforo disponível, conseqüentemente diminuindo a utilização da proteína dietética e causando um aumento na suplementação de fitase para melhorar a utilização do fósforo não disponível (fitato) e conseqüentemente melhorar o desempenho dos alevinos de tambaqui do trabalho.

As variáveis ao desenvol-vimento dos alevinos de tambaqui apresen-taram um comportamento quadrático (tabela IV).

Para as variáveis, consumo de ração (CR), conversão alimentar aparente (CAA) e taxa de eficiência protéica (TEP), os valores de suplementação de fitase na ração que correspondem de forma mais eficiente são; 1540,$62 ; 1796,90$ e 1760,35 , respectivamente.

Esses valores foram estimados através das seguintes equações:

$C R=26,0098-0,00526505 x+0,00000170874 x^{2}$ $\left(R_{\text {ajust }}^{2}=0,63\right)$,

CAA $=1,74383-0,000652834 x+0,000000181656 x^{2}$ $\left(R_{\text {ajust. }}^{2}=0,60\right)$,
Taxa de eficiência protéica $=2,17359+0,00109536 \mathrm{x}$ $0,00000031112 x^{2}\left(R_{\text {ajust. }}^{2}=0,55\right)$.

Souza (2008) observou uma piora na conversão alimentar dos peixes que receberam dietas com fitase em comparação aos que consumiram dieta com fosfato bicálcico. Mesmo quadro foi observado para a truta arco-íris (Vielma et al., 2004) e para a tilápia do Nilo, quando as dietas foram suplementadas com fitase em níveis de 500 a 1250 UFA/kg da dieta (Liebert e Portz, 2005). Em estudos com o salmão do Atlântico e carpa comum, Nwanna e Schwarz (2007) indicaram que a fitase estimula o apetite dos peixes levando à piora na conversão alimentar.

Contradizendo estes resultados, o presente trabalho através da coleta de dados e da analise estatística estimou que a suplementação de fitase melhorou significativamente a conversão alimentar atingindo seu ápice na dose de 1796,90 UFA/kg de ração, o mesmo foi abservado para outras espécies em outros trabalhos como o de Jackson et al. (1996) com juvenis de catfish, por Furuya et al. (2001) para a tilápia do Nilo, por Debnath et al. (2005) com alevinos de $P$. pangasius e por Baruah et al. (2007) com o L. rohita.

A maior retenção de proteína pelos

Tabela IV. Ganho de peso (GP), consumo de ração (CR), conversão alimentar aparente $(C A A)$, taxa de crescimento especifico (TCE), taxa de desenvolvimento especifico (TDE) e taxa de eficiência protéica (TEP) dos alevinos de tambaqui com suplementação de fitase. (Weight gain (GP), feed intake (CR), feed conversion ratio (CAA), specific growth rate (TCE), specific rate of development (TDE) and protein efficiency ratio (TEP) of tambaqui fingerlings supplemented with phytase).

\begin{tabular}{lcccccc}
\hline & \multicolumn{5}{c}{ Tratamentos (UFA/kg de ração) } \\
& 0 & 700 & 1400 & 2100 & 2800 & CV \\
\hline GP (g/dia) & 14,88 & 17,29 & 18,65 & 18,60 & 18,75 & 9,36 \\
CR (g) & 15,22 & 17,17 & 19,58 & 19,19 & 20,12 & 11,11 \\
CAA & 1,02 & 1,00 & 1,06 & 1,03 & 1,08 & 3,03 \\
TCE (\%) & 3,49 & 3,77 & 3,88 & 3,86 & 3,91 & 4,55 \\
TDE (\%) & 1,14 & 1,21 & 1,24 & 1,22 & 1,25 & 3,60 \\
TEP (\%) & 3,49 & 3,60 & 3,40 & 3,47 & 3,33 & 2,87 \\
\hline
\end{tabular}

Archivos de zootecnia vol. 61, núm. 235, p. 442. 
peixes que receberam as rações com maior inclusão de fitase provavelmente está relacionada com a maior disponibilidade do fósforo (Yoo et al., 2005) nas rações suplementadas com fitase. Segundo Denstadli et al. (2007), a fitase aumenta a disponibilidade do fósforo na matéria prima utilizada para formulação de rações e conseqüentemente a digestibilidade da proteína. A fitase ainda aumenta a digestibilidade dos aminoácidos (Sugiura et al., 2001), e alguns minerais como zinco, magnésio, cobre e ferro (Masumoto et al., 2001).

Observa-se valores próximos entre a resposta da TEP para o tratamento sem suplementação e os tratamentos acima de 1400 UFA/kg de ração. Vários estudos relatam a eficiência da suplementação de enzimas ou complexos enzimáticos sobre o desenvolvimento dos peixes como Vielma et al., 1998; Furuya et al., 2004; Gonçalves et al., 2004; Sajjadi e Carter, 2004; Bock et al., 2006; Furuya et al., 2006; Silva et al., 2007; Rocha et al., 2008). Entretanto, Gonçalves et al. (2007), observaram que a suplementação ou não de fitase na ração ao nível de 1000 e 2000 UF/kg de ração não afetou a digestibilidade do farelo de trigo e do farelo de algodão. Furuya et al. (2005) também não observaram diferença entre a suplementação ou não de fitase para as variáveis taxa de eficiência protéica, peso final, conversão alimentar e sobrevivência utilizando ração com $25 \%$ de proteína bruta e para variável rendimento de carcaça com ração contendo $28 \%$ de proteína bruta.

Os menores valores observados em relação a taxa de eficiência protéica dos peixes alimentados sem suplementação ou com excesso de suplementação de fitase possivelmente está associada a possível inibição da ß-oxidação dos ácidos graxos que resultou em menor utilização dos lipídios como fonte de energia, sendo utilizada a proteína como fonte alternativa de energia, o que reduziu a utilização da proteína (Roy e Lall, 2003). Por outro lado, a menor utilização da proteína pelos peixes que receberam die- tas com altos valores de fitase na ração, pode estar relacionada com o maior valor de fósforo disponível, que pode ter inibido a utilização de minerais como: cálcio, zinco, magnésio e ferro (Furuya et al., 2008).

Alem da TEP, do CR e da CAA, outra variável que e afetada diretamente devido a utilização de proteína pelo peixe e o ganho de peso (GP), a taxa de crescimento especifico (TCE) e a taxa de desenvolvimento especifico (TDE). Essas variáveis demonstraram um comportamento quadrático com o máximo de resposta a suplementação com fitase, quando a dose de suplementação chega a 2145,$77 ; 2170,67$ e 2303,83 UFA/ kg de ração, respectivamente.

$$
\begin{aligned}
& G P=14,9791+0,00371622 x-0,000000865942 x^{2} \\
& \left(R^{2}{ }_{\text {ajust. }}=0,96\right), \\
& T C E=3,50879+0,000375008 x-0,000000181656 x^{2} \\
& \left(R^{2}{ }_{\text {ajust. }}=0,90\right), \\
& T D E=1,14528+0,000086819 x-0,000000188423 x^{2} \\
& \left(R_{\text {ajust. }}^{2}=0,81\right) .
\end{aligned}
$$

O comportamento quadrático das variáveis mencionadas acima esta relacionado aos efeitos positivos e negativos que pode ter a suplementação de fitase quando e feita de forma excessiva. Esta pode afetar a digestibilidade da proteína e a disponibilidade de minerais, o que podem favorecer ou não a absorção intestinal (Rocha et al., 2007).

Os resultados do presente trabalho diferem dos observados por Hugues e Soares (1998), que avaliaram a suplementação de diferentes níveis de fitase $(0,800$; 1300 e $2400 \mathrm{FTU} \mathrm{kg}^{-1}$ dieta) e fósforo inorgânico $\left(\mathrm{K}^{2} \mathrm{PO}^{4}\right)$, não encontrando efeito dos níveis de fitase sobre o ganho de peso entre os tratamentos para o striped bass (Morone saxatilis).

Cerca de $67 \%$ do fósforo total presente nas sementes de oleaginosas, grãos de cereais e seus subprodutos encontra-se na forma de fitato, de baixa disponibilidade para os peixes (NRC, 1993). A adição de fitase resulta em aumento 58,82\% na 
disponibilidade do fósforo do farelo de soja integral (Silva et al., 2005).

Os efeitos positivos da suplementação de fitase sobre a utilização do fósforo fítico já foram demonstrados em estudos realizados com a truta arco-íris por Lanari et al. (1998) e Vielma et al.(2000). O aumento na disponibilidade do fósforo do farelo de canola suplementado com fitase também foi obtido por Richie e Brown (1996) e Forster (1999), em trabalho realizado com essa mesma espécie.

Já em trabalhos realizados por Rodehutscord e Pfeffer (1995), Lanari et al. (1998) com a truta arco-íris, os maiores valores de ganho de peso foram obtidos pelos peixes que consumiram ração com $1000 \mathrm{UF} / \mathrm{kg}$ de ração. Outro trabalho realizado com truta arco-íris foi o de Vielma et al. (1998), em que observaram maior valor desta variável no tratamento que recebeu ração contendo 1500 $\mathrm{UF} / \mathrm{kg}$ de dieta, sendo inferior também ao valor determinado pelo presente trabalho, porem bem mais próximo.

O valor estimado para suplementação de fitase no presente trabalho para a variável GP, está próximo ao encontrado por Furuya et al. (2008) que observaram resposta linear a suplementação de fitase na ração para alevinos de pacu, com o maior valor de suplementação testado equivalente a 2000 $\mathrm{UF} / \mathrm{kg}$ de ração, sobre o ganho de peso, sendo uma resposta linear, podemos esperar que a dose máxima para essa variável fique acima de $2000 \mathrm{UF} / \mathrm{kg}$ de ração.

A taxa de desenvolvimento específico (TDE) e a taxa de crescimento específico (TCE) são variáveis que demonstram como o animal evolui em comprimento e em peso durante os dias do experimento, respectivamente. A TCE encontrada na tabela IV difere dos resultados obtidos por Mendonça et al. (2009) também trabalharam com alevinos de tambaqui e encontraram valores ainda menores em relação a taxa de crescimento especifica para os tratamentos com diferentes fotoperíodos $(1,13 ; 1,26 ; 1,24$ e 1,45$)$. Porem os animais desse trabalho (Mendonça et al., 2009) não foram alimentados com ração balanceada para a espécie e nem suplementada com nenhum tipo de substância promotora de crescimento, isso pode explicar os valores estão abaixo dos encontrados no presente trabalho.

Valores de TCE abaixo dos apresentados no presente trabalho também são descritos por Santos et al. (2010), que trabalharam com níveis de proteína após período de privação alimentar para alevinos de tambaqui e observaram que a medida que aumentava os níveis protéicos, maior era o valor da TCE, sendo a maior resposta com ração contendo $36 \%$ de proteína bruta. Valor este de proteína superior ao utilizado no presente trabalho $28 \%$ de proteína bruta

Já Signor et al. (2010) trabalharam com suplementação de complexo enzimático para juvenis de tilápia do Nilo com peso médio inicial de $14,57 \pm 1,24 \mathrm{~g}$, que também continha enzima fitase, não observaram diferença significativa entre os valores de TCE obtidos com as suplementações.

Rocha et al. (2007) observaram efeito linear para a taxa de crescimento específico (TCE) dos alevinos de jundiá até o nível de $1500 \mathrm{FTU} / \mathrm{kg}$ de ração. O aumento linear observado por Rocha et al. (2007) na TCE com o incremento dos níveis de fitase na dieta pode estar relacionado com os efeitos positivos da fitase sobre a digestibilidade protéica e a disponibilidade de minerais, favorecendo sua absorção intestinal. O mesmo foi observado por Portz e Liebert (2004) para juvenis de tilápia do Nilo (Oreochromis niloticus) até o nível de 2000 FTU/kg de ração.

O fósforo geralmente é o nutriente mais limitante em grãos de cereais usados na elaboração de dietas para peixes. É um nutriente essencial e sua deficiência leva a uma redução na taxa de crescimento, redução na eficiência alimentar, baixa mineralização óssea (Furuya et al., 2001). A suplementação com fitase contribui para o aumento da disponibilidade dos amino-ácidos e minerais como o cálcio, zinco, mag- 


\section{FITASE PARA JUVENIS DE TAMBAQUI}

nésio, cobre e ferro (Sugiura et al., 2001).

Vários estudos têm sido realizados para avaliar os efeitos da enzima fitase sobre o desempenho e a disponibilidade dos minerais, principalmente o fósforo. Os efeitos da suplementação de fitase sobre a digestibilidade da energia bruta e dos nutrientes foram demonstrados em trabalhos realizados com a truta arco-íris (Oncorhynchus mykiss) por Lanari et al. (1998) e Forster (1999), com salmão do Atlântico (Salmo salar) por Sajjadi e Carter (2004), com striped bass (Morone saxatilis) por Papatryphon e Soares (2001) e com a tilápia do Nilo (Oreochromis niloticus) por Furuya et al. (2001).

Bock et al. (2007), trabalharam com níveis de suplementação variando de 1000 a 2000 $\mathrm{UF} / \mathrm{kg}$ na dieta da tilápia do Nilo e não melhoraram o desempenho produtivo, apesar de reduzirem os níveis de fósforo nas fezes. Nwanna e Schwarz (2007) testaram a inclusão de três níveis de fitase (1000, 2000 e $4000 \mathrm{UF} / \mathrm{kg}$ ) na dieta da carpa comum e não observaram efeito sobre o desempenho. Esses autores sugeriram níveis maiores de fitase para uma possível melhora no desempenho produtivo.

A taxa de atividade de hidrólise da enzima na temperatura do presente trabalho pode ter influenciando a resposta da suplementação, uma vez que a temperatura

\section{BIBLIOGRAFIA}

Araujo-Lima, C.A.R.M. e Gomes, L.C. 2005. Tambaqui (Colossoma macropomum). In: Baldisserotto, B., Gomes, L.C. (Eds.). Espécies nativas para piscicultura no Brasil. $1^{\text {a }}$ ed. Santa Maria. Ed. da UFSM. pp. 468.

Aride, P.H.R., Roubach, R. and Val, A.L. 2004. Water $\mathrm{pH}$ in central Amazon and its importance for tambaqui (Colossoma macropomum) culture. World Aquacult, Baton Roude, 35: 2427

Baruah, K., Suhu, N.P., Pal, A.K., Jain, K.K., Debnath, D. and Mukherjee, S.C. 2007. Dietary microbia phytase and citric acid synergistically enhances se manteve em $28^{\circ} \mathrm{C}$. E a temperatura e o $\mathrm{pH}$ ideal para atividade de hidrólise da fitase é superior aos $30^{\circ} \mathrm{C}$ e 5,3 , respectivamente Sugiura et al. (2001).

Baruah et al. (2007) relataram que, em peixes carnívoros, o baixo $\mathrm{pH}$ estomacal facilita a ação de enzimas digestivas, inclusive a fitase. Em peixes onívoros, esse mecanismo é reduzido, devido ao valor do $\mathrm{pH}$ do estômago dessas espécies. Como alternativa, poderiam ser utilizados ácidos orgânicos ou acidificantes na dieta para melhorar a atividade enzimática (Li et al., 2008).

O pré-tratamento das dietas com fitase, ou a inclusão de ácidos orgânicos, pode ser uma alternativa para melhorar o efeito desta enzima em peixes onívoros (Rocha et al., 2010). É importante mencionar, também, que a ação e o resultado dos níveis de fitase empregados estão relacionados com o valor biológico dos alimentos, a natureza e a quantidade de ácido fítico que estes possam conter (Gonçalves et al., 2004).

\section{CONCLUSÃO}

A suplementação de fitase na dieta influencia o desenvolvimento de alevinos de tambaqui (Colossoma macropomum). Entretanto, concentrações mais altas são necessárias que as recomendadas em comparação à literatura disponível.

nutrient digestibility and growth performance of Labeo rohita (Hamilton) juveniles at sub-optimal protein level. Aquacult Res, 38: 109-120.

Bock, C.L., Pezzato, L.E., Cantelmo, O.A. e Barros, M.M. 2006. Fitase e digestibilidade aparente de nutrientes de rações por tilápias do Nilo. Rev Bras Zootecn, 35: 2197-2202.

Bock, L.C., Pezzato, L.E., Cantelmo, O.A. e Barros, M.M. 2007. Fitase em rações para tilápia-do-nilo na fase de crescimento. Rev Bras Zootecn, 36: 1455-1461.

Debnath, D., Pal, A.K., Sahu, N.P., Jain, K.K., Yengkokpam, S. and Mukherjee, S.C. 2005. 


\section{MENDONÇA, COSTA, POLESE, VIDAL JR E ANDRADE}

Effect of dietary microbial phytase supplementation on growth and nutrient digestibility of Pangasisu pangasius (Hamilton) firgerlings. Aquacult Res, 36: 180-187.

Denstadli, V., Storebakken, T., Svihus, B. and Skrede, A. 2007. A comparison of online phytase pre-treatment of vegetable feed ingredients and phytase coating in diets for Atlantic salmon (Salmo salar L.) reared in cold water. Aquaculture, 269: 414-426.

Forster, I., Higgs, D.A. and Dosanjh, B.S. 1999. Potential for dietary phytase to improve the nutritive value of canola protein concentrate and decrease phosphorus output in rainbow trout (Oncorhynchus mykiss) held in $11^{\circ} \mathrm{C}$ fresh water. Aquaculture, 179: 109-125.

Furuya, W.M., Pezzato, L.E., Pezzato, A.C., Barros, M.M. e Miranda, E.C. 2001. Coeficientes de digestibilidade e valores de aminoácidos digestíveis de alguns ingredientes para a tilápia do Nilo (Oreochomis niloticus). Rev Bras Zootecn, 30: 1143-1149.

Furuya, W.M., Botaro, D., Silva, L.C.R., Dos Santos, V.G., Silva, T.S.C., Dos Santos, L.D. e Furuya V.R.B. 2006. Fitase em dietas para tilápia do Nilo (Oreochromis niloticus) (175 a 327 G). Arch Zootec, 55: 161-170.

Furuya, W.M., Michelato, M., Silva, L.C.R., Santos L.D., Silva, T.S.C., Schamber, C.R., Vidal, L.V.O e Furuya, V.R.B. 2008. Fitase em rações para Juvenis de pacu (Piaractus mesopotamicus). Bol Inst Pesca, 34: 489-496.

Furuya, W.M., Neves, P.R., Silva, L.C.R., Botaro, D., Hayashi, C. e Sakaguti, E.S. 2004. Fitase na alimentação da tilápia do Nilo (Oreochromis niloticus), durante o período de reversão de sexo. Acta Sci Anim Sci, 26: 299-303.

Furuya, W.M., Santos, V.G., Botaro, D., Hayashi, C. e Silva, L.C.R. 2005. Níveis de proteína e fitase em rações de terminação para a tilápiado-nilo (Oreocrhomis niloticus). Arq Cienc Vet Zool Unipar, 8: 11-17.

Gonçalves, G.S., Pezzato, L.E. e Barros, M.M. 2004. Digestibilidade aparente e suplementação de fitase em alimentos vegetais para tilápia-donilo. Acta Sci Anim Sci, 26: 313-321.

Gonçalves, G.S., Pezzato, L.E., Padilha, P. e Barros, M.M. 2007. Disponibilidade aparente do fósforo em alimentos vegetais e suplementação da enzima fitase para tilápia-do-nilo. Rev Bras
Zootecn, 36: 1473-1480.

Helland, S., Denstadli, V., Witten, P.E., Hjelde, K., Storebakken, T. and Skrede, A. 2006. Hyperdense vertebrae and mineral content in Atlantic salmon (Salmo salar L.) fed diets with graded levels of phytic acid. Aquaculture, 261: 603614.

Hughes, K.P. and Soares Jr, J.H. 1998. Efficacy of phytase on phosphorus utilization in practical diets fed to striped bass Morone saxatilis. Aquacult Nutr, 4: 133-140.

Jackson, L.S., Li, M.H. and Robinson, E.H. 1996. Use of microbial phytase in channel catfish Ictalurus punctatus diets to improve utilization phytate phosphorus. J World Aquacult Soc, 27: 309-313.

Kornegay, E.T. 1999. Feeding to reduce nutrient excretion: effects of phytase on phosphorus and other nutrients. Kin: Lyons, T.P., Jacques, K.A. (Eds.). Biotechnology in the feed industry. University Press. Nottingham. pp. 461-489.

Lanari, D., D'agaro, E. and Turri, C. 1998. Use of nonlinear regression to evaluate the effects of phytase enzyme treatment of protein plant diets for rainbow trout (Oncorhynchus mykiss). Aquaculture, 161: 345-356.

Lehninger, A.L., Nelson, D.L. and Cox, M.M. 1993. Principles of biochemistry. $2^{\text {nd }}$ ed. New York: Worth. 1013 pp.

Li, J.S., Li, J.L. and Wu, T.T. 2008. Effects of nonstarch polissacarides enzyme, phytase and citric acid on activities os endogenous digestive enzymes of tilapia (Oreochromis niloticus $x$ Oreochromis aureus). Aquacult Nutr, 15: 415420.

Liebert, F. and Portz, L. 2005. Nutrient utilization of Nile tilapia Oreochromis niloticus fed plant based low phosphorus diets supplemented with graded levels of different sources of microbial phytase. Aquaculture, 248: 111-119.

Lovell, T. 1988. Nutrition and feeding of fish. Audum University. Alabama.

Masumoto, T., Tamura, B. and Fhimeno, S. 2001. Effects of phytase on bioavailability of phosphorus in soybean meal-based diets for Japaneses flounder Paralichthys olivaceus. Fisheries Sci, 67: 1075-1080.

Mendonça, P.P., Ferreira, R.A., Vidal Junior, M.V., Andrade, D.R., Santos, M.V.B., Ferreira, A.V. e Rezende, F.P. 2009. Influência do fotoperíodo 


\section{FITASE PARA JUVENIS DE TAMBAQUI}

no desenvolvimento de juvenis detambaqui (Colossoma macropomum). Arch Zootec, 58: 323-331.

Menezes, A. 2005. Aqüicultura na pratica: peixes, camarões, ostras, mexilhões e sururus. Hoper Editora. Espírito Santo. 107 pp.

MPA. 2009. Ministério da Pesca e Aquicultura. Boletim Estatístico da Pesca e Aquicultura. $1^{a}$ Ed. $101 \mathrm{pp}$.

NRC. 1993. National Research Council- Nutritional Requirements of fishes. Academic Press. Washington.

Nwanna, L.C. and Schwarz, F. 2007. Effect of supplementation phytase on growth, phosphorus digestibility and bone mineralization of common carp (Cyprinus carpio L.). Aquacult Res, 38: 1037-1044.

Papatryphon, E. and Soares, J.H. 2001. The effect of phytase on apparent digestibility of four practical plant feedstuffs fed to striped bass Morone saxatilis. Aquacult Nutr, 7: 161-167.

Portz, L. and Liebert, F. 2004. Growth, nutrient utilization and parameters of mineral metabolism in Nile tilapia Oreochromis niloticus (Linnaeus, 1758) fed plant-based diets with graded levels of microbial phytase. J Anim Physiol An N, 88 : 311-320.

Richie, M. and Brown, P.B. 1996. Availability of phosphorus from feedstuffs to rainbow trout, Oncorhynchus mykiss. Aquaculture, 142: 269282

Rocha, C.B., Poueyn, J.L.O.F., Enke, D.B.S., Xavier, E.G. e Almeida, D.B. 2007. Suplementação de fitase microbiana na dieta de alevinos de jundiá: efeito sobre o desempenho produtivo e as características de carcaça. Ciênc Rural, 37 1772-1778.

Rocha, C.B., Pouey, J.L.O.F., Lopes, P.R.S., Enke, D.B.S. e Xavier, E.G. 2008. Suplementação da enzima fitase e o desempenho e retenção mineral em juvenis de jundia (Rhamdia quelen). Bol Inst Pesca, 34: 153-159.

Rocha, C.B., Pouey, J.L.F., Piedra, S.S.R.N., Enke, D.B.S. e Fernandes, J.M. 2010. Fitase na dieta de alevinos de carpa húngara: desempenho e características de carcaça. Arq Bras Med Vet Zootec, 62: 1462-1468.

Rodehutscord, M. and Pfeffer, E. 1995. Effects of supplemental microbial phytase on phosphorus digestibility and utilization in rainbow trout
(Oncorhynchus mykiss). Water Sci Technol, 31: 143-147.

Rostagno, H.S., Silva, D.J., Costa, P.M.A., Fonseca, J.B., Soares, P.R., Pereira, J.A.A. e Silva, M.A 1983. Composição de alimentos e exigências nutricionais de aves e suínos. Tabelas brasileiras. UFV. Viçosa. 50 pp.

Roy, P.K. and Lall, S.P. 2003. Dietary phosphorus requirement of juvenile haddock (Melanogrammus aeglefinus L.). Aquaculture, 221: 451-468.

SAEG. 2007. Sistema para Análises Estatísticas, Versão 9.1. Fundação Arthur Bernardes. UFV. Viçosa.

Sajjadi, M. and Carter, C.G. 2004. Dietary phytase supplementation and the utilization of phosphorus by Atlantic salmo (Salmo salar L.) fed a canola-neal-based diet. Aquaculture, 240: 417-431.

Santos, L., Pereira Filho, M., Sobreira, C., Ituassú D. e Fonseca, F.A.L. 2010. Exigência protéica de juvenis de tambaqui (Colossoma macropomum) após privação alimentar. Acta Amazônica, 40: 597-604.

Signor, A.A., Boscolo, W.R., Bittencourt, F., Feiden, A., Gonçalves, G.S. e Freitas, J.M.A. 2010. Desempenho de juvenis de tilápia-do-nilo alimentados com rações contendo complexo enzimático. Rev Bras Zootecn, 39: 977-983.

Silva, T.S.C., Furuya, W.M., Santos, V.G., Botaro, D., Silva, L.C.R., Sales, P.J.P., Hayashi, C., Santos, L.D. e Furuya, V.R.B. 2005. Coeficientes de digestibilidade aparente da energia e nutrientes do farelo de soja integral sem e com fitase para a tilápia do Nilo (Oreochromis niloticus). Acta Sci Anim Sci, 27: 371-376.

Silva, T.S. de C., Furuya, W.M., Santos, L.D. dos, Fujii, K.M., Michelato, M. e Iwamoto, B.S. 2007. Fitase líquida em dieta extrusada para juvenis de tilápia do Nilo (Oreochromis niloticus). Acta Sci Anim Sci, 29: 449-455.

Souza, S.R. 2008. Fitase em dietas para Matrinxã (Brycon cephalus) e Piavuçu (Leporinus macrocephalus). Tese (Doutorado em Zootecnia). Universidade Estadual de Maringá. Maringá, PR. 34 pp.

Sugiura, S.H., Gabaudan, J., Dong, F.M. and Hardy, R.W. 2001. Dietary microbial phytase supplementation and the utilization of phosphorus, trace minerals and protein by rainbow trout 


\section{MENDONÇA, COSTA, POLESE, VIDAL JR E ANDRADE}

[Oncorhynchus mykiss (Walbaum)] fed soybean meal-based diets. Aquacult Res, 32: 583-592.

Vidal Junior, V.V. 1995. Níveis de proteína para tambaqui (Colossama macropomum Curvier, 1818) dos 30 aos $250 \mathrm{~g}$ de peso vivo. Tese. Mestrado em Zootecnia. Universidade Federal de Viçosa (UFV). Viçosa, MG. pp. 49.

Vielma, J., Lall, S.P. and Koskela, J. 1998. Effects of dietary phytase and cholecalciferol on phosphorous bioavailability in rainbow trout (Oncorhynchus mykiss). Aquaculture, 163: 309-323.

Vielma, J., Mäkinen, T., Ekholm, P. and Koskela, J. 2000. Influence of dietary soy and phytase levels on performance and body composition of large rainbow trout (Oncorhynchus mykiss) and algal availability of phosphorus load. Aquaculture, 183: 349-362.

Vielma, J., Ruohonen, K., Gabaudan, J. and Vogel, K. 2004. Top-spraying soyben meal-based with phytase improves protein and mineral digestibilities but not lisine utilization in rainbow trout, Oncorhynchus mykiss (Walbaum). Aquacult Res, 35: 955-964.

Yoo, G., Wang, X., Choi, S., Hana, K., Kangb, J. and Baia, S.C. 2005. Dietary microbial phytase increased the phosphorus digestibility in juvenile Korean rockfish Sebastes schlegeli fed diets containing soybean meal. Aquaculture, 243: 315-322.

Archivos de zootecnia vol. 61, núm. 235, p. 448. 